\title{
Salomón Wilfredo Zavala Sarrio (1933-2021) Un recuerdo y un homenaje póstumo al maestro y amigo
}

\section{Salomón Wilfredo Zavala Sarrio (1933-2021) A memory and posthumous tribute to the teacher and friend}

Eddy Luz Juárez-Severino'

El Dr. Salomón Wilfredo Zavala Sarrio, nació en la ciudad de Tarma, un 8 de abril del año 1933, realizó sus estudios secundarios becado en el Colegio América-Callao High School.

Curso su carrera universitaria en la Facultad de Medicina de San Fernando, de la Universidad Nacional Mayor de San Marcos (UNMSM) graduándose como médico cirujano en 1963, egresando como integrante de la Promoción Reforma, habiendo participado en memorables jornadas estudiantiles, como presidente del Centro de Estudiantes de Medicina, cargo que desempeño en varios períodos, en la época de mayor crisis de la facultad y de la universidad.

En la misma facultad de medicina realizó las especialidades de medicina interna y de medicina intensiva, obteniendo el doctorado en medicina en 1979 y la maestría en bioética en el año 2002.

Sus actividades hospitalarias se iniciaron como asistente libre, en el Hospital de Varones Daniel A. Carrión, en la Sala de Medicina San Miguel, hospital de la Beneficencia Pública del Callao, en ese entonces, realizando esta labor sin ninguna retribución económica, ni compromiso laboral, pero con responsabilidad y mostrando gran responsabilidad social, acudiendo diariamente a realizar la visita de los pacientes.

En el año 1969, mediante un concurso público realizado en este hospital, logra ingresar como médico asistente del Departamento de Medicina.

Médica internista
Juárez-Severino EL. Salomón Wilfredo Zavala Sarrio (1933-202I). Rev Soc Peru Med Interna. 2021;34(3):126.

https://doi.org/10.36393/spmi.v34i3.617

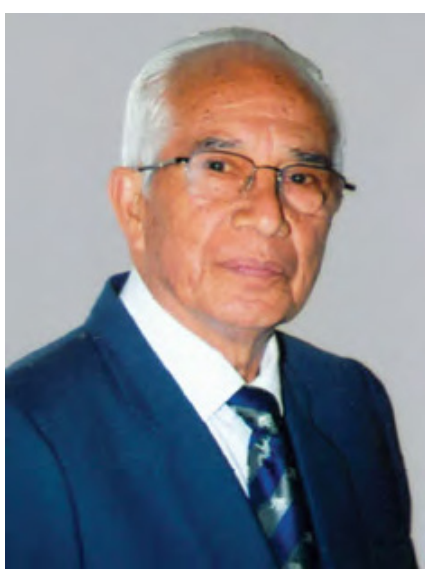

Dr. Salomón Wilfredo Zavala Sarrio

$\mathrm{Su}$ inquietud por la atención de pacientes en estado crítico, conjuntamente con el doctor Manuel Echecopar Benavides, el apoyo técnico de la Organización Panamericana de la Salud (OPS), y con equipos donados por la Fundación Kellog, hicieron posible que se instalara en el Hospital Carrión del Callao, la primera Unidad de Cuidados Intensivos del Perú, la misma que se inauguró el día 13 de mayo de 1971, siendo el Dr. Salomón Zavala el médico jefe, cargo que desempeñó por un período de 20 años.

Su preocupación por la necesidad contar con médicos de la especialidad de medicina intensiva lo llevó a impulsar su formación y dar su apoyo con su experiencia en la creación de otras unidades de cuidados intensivos. El crecimiento de esta especialidad, lo llevo a fundar, en el año 1978, la Sociedad Peruana de Medicina Intensiva, siendo su primer presidente. 
En el campo gremial e institucional, fue presidente del Cuerpo Médico del Hospital (1986-1988), desarrollando una labor importante para brindar mejores condiciones para la atención de los pacientes.

A propuesta del Cuerpo Médico, fue nombrado director del Hospital Daniel A. Carrión, desde agosto de 1990 a diciembre de 1991. Posteriormente, fue viceministro de Salud por un periodo de dos años (1991-1993).

En el año 1998 fue elegido decano del Consejo Regional IIILima, del Colegio Médico del Perú.

En 1999 fue miembro fundador y primer vicepresidente de la Academia Peruana de Salud.

Su preocupación por el aspecto de la ética y salud lo llevo a la participación activa en este tema de tanta importancia. Fue presidente por 15 años del Comité de Ética de investigación de la Asociación Benéfica Prisma, desde el año 1999. En el año 2000, fue nombrado miembro del Comité de Ética de Investigación del Instituto Nacional de Salud.

En el año 2003, fundó el Comité de Ética de Investigación del Hospital Daniel A. Carrión del Callao, siendo su primer presidente.

En el año 2003 fue miembro fundador del Instituto de Ética en Salud de la Facultad de Medicina de San Fernando, UNMSM, y subdirector desde el año 2011 al 2013.

En el período 2007 -2008 fue presidente de la Sociedad Peruana de Medicina Interna, integrando la comisión de alto nivel que revisó y redactó el actual Código de Ética del Colegio Médico del Perú.

Su carrera docente se inició en el año de 1971, ingresando mediante concurso, como jefe de prácticas de los cursos de semiología y medicina interna en la Sede Docente del Hospital Daniel A. Carrión, llegando a la categoría de profesor principal de la Facultad de Medicina de la UNMSM. En el año 2007 fue nombrado jefe de la Sección Doctoral de la Unidad de Posgrado de la Facultad de Medicina de la UNMSM

Fue encargado de los cursos de políticas sociales de salud en el doctorado de neurociencias, bioética y deontología en la maestría de salud pública, ética en el doctorado de medicina y bioética en el doctorado de ciencias de la salud.

Desarrolló la carrera docente en la Facultad de Medicina de la UNMSM durante 47 años, ocupando diversos cargos académicos en pre y posgrado.

El reconocimiento al maestro, su calidad como docente, su humanidad y compromiso, se refleja en el recuerdo y agradecimiento de quienes fueron sus alumnos y hoy son profesionales comprometidos.

Ha sido autor de diversos artículos y publicaciones sobre cuidados y prevención de la salud, como el manual "Yo cuido mi salud", dirigido a estudiantes y profesores. Durante cuatro años, publicó en el diario Gestión, una página semanal sobre temas de salud, habiendo elaborado el proyecto del semanario Gestión Medica. Tiene otras publicaciones sobre ética en salud y relación médico paciente, como" El doctor no me informó" y "Esa maldita palabra de seis letras. Viviendo con el cáncer", los mismos que muestran su preocupación para el trato al paciente. También escribió algunos temas en versos.
Ha recibido reconocimientos y distinciones otorgadas por diversas instituciones, entre ellas, de la Facultad de Medicina de San Fernando. También el Colegio Médico del Perú le otorgó Medalla al Mérito Extraordinario. Es epónimo del Premio a la Investigación, instituido por la SPMI y que es entregado cada dos años. Fue reconocido por el Congreso de la Republica, el 5 de octubre del 2018, Día de la Medicina Peruana, como Gran Maestro, en virtud de sus valores académicos, éticos, docentes y de su brillante carrera profesional al servicio del país.

Otra faceta que refleja la personalidad del Dr. Salomón Zavala, sumada a su buen humor y espontaneidad, fue la de deportista, fue integrante de los equipos de fulbito desde su paso por las aulas de San Fernando, hasta el equipo del Hospital Carrión del Callao, ganando en muchas ocasiones copas, medallas y reconocimientos. Esta actividad la practicó hasta estos últimos años.

No podemos dejar de mencionar su entorno familiar, con su esposa Gloria A. Soriano P. formaron, siendo muy jóvenes, un matrimonio que, a través de sus 60 años, con sus tres hijos (Enrique, Gustavo, Andrés) y sus cinco nietos fueron siempre motivo de que se expresara feliz y pleno de bendiciones en su vida familiar.

Quienes tuvimos la suerte de compartir con él, a través de muchos años, cada día las actividades hospitalarias, de docencia, de gestión, gremiales, no olvidaremos su calidad como persona, como compañero de trabajo, como maestro, su compromiso como profesional, su preocupación por la atención de cada paciente y por las condiciones de la institución.

Hemos tenido la oportunidad de contar con el maestro y el amigo dispuesto a dar el apoyo incondicional, aún sin pedírselo, hemos tenido la suerte de contar con su gran amistad.

Salomón Zavala Sarrio, nos dejó físicamente el 27 de junio de este 2021, pero siempre estará en nuestro recuerdo.

Termino esta reseña con estas líneas que a la muerte de su esposa, en 2016) le dedica el Dr. Salomón Zavala.

\section{Para Gloria, de Salomón Ella me espera \\ En un lugar del planeta / De ubicación / No escogida / Ella me estaba / Aguardando / En fecha hoy conocida. / Sesenta años después / He llorado / Su partida / Por un tiempo / Sin medida / Este se ha vuelto / El inicio / De una historia / Ignorada. / \\ En algún lugar / Del orbe / Donde van / Las almas nobles / Ella me espera.}

\section{CORRESPONDENCIA:}

Eddy Luz Juárez-Severino, eddyluzjs@yahoo.es

Fecha de recepción: |6-08-202|.

Fecha de aceptación: 23-08-2021.

Conflicto de interés: ninguno, según la autora.

Financiamiento: por la autora. 